\title{
Reproductive characteristics and semen quality in maiden Dutch Warmblood stallions
}

\author{
J. M. Parlevliet ${ }^{1}$, B. Kemp ${ }^{2}$ and B. Colenbrander ${ }^{1}$ \\ ${ }^{I}$ Department of Herd Health and Reproduction, Faculty of Veterinary Medicine, University of Utrecht, \\ Yalelaan 7, 3584 CL Utrecht, The Netherlands; and 'Department of Animal Husbandry, Agricultural \\ University, PO Box 338, 6700 AH Wageningen. The Netherlands
}

\begin{abstract}
The semen characteristics and testicular size of 398 3-year-old maiden Dutch Warmblood stallions were studied during February and March. Mean values $( \pm \mathrm{SD})$ of age (1030 \pm 88 days) and testicular size $(9.8 \pm 0.9 \mathrm{~cm})$ of the maiden stallions were determined as well as the following semen characteristics (mean of two ejaculates, taken $\mathrm{Ih}$ apart): volume $(65 \pm 26 \mathrm{ml})$, sperm concentration $\left(2.061 \pm 1.685 \times 10^{8} \mathrm{ml}^{-1}\right)$, total number of spermatozoa $\left(1.129 \pm 0.71 \times 10^{10}\right)$, percentage of progressively motile spermatozoa $(68 \pm 9 \%)$, percentage of live spermatozoa with normal morphology ( $66 \pm 15 \%$ ), total number of progressively motile morphologically normal spermatozoa $\left(5.307 \pm 3.833 \times 10^{9}\right)$ and $\mathrm{pH}(7.5 \pm 0.2)$. The morphology of the spermatozoa was studied and data on the most common abnormalities are presented. The first and second ejaculates show significant differences $(P<0.05)$ in volume, motility, number of spermatozoa, sperm morphology, total number of progressively motile morphologically normal spermatozoa and $\mathrm{pH}$. The original breed has been split up into two different lines. There was a significant difference $(P<0.05)$ in semen characteristics between the types (riding and carriage horses). The semen quality and quantity of semi-siblings were compared and a significant sire effect $(P<0.05)$ was shown for the following characteristics: volume, motility (\%) and sperm concentration. These results indicate that there are differences of heritability of those factors, which makes it possible to select on semen quality.
\end{abstract}

\section{Introduction}

Semen of good fertilizing capacity is a prerequisite for obtaining good fertility results on a studfarm. The large number of mares to be bred by one stallion (up to 300 per year), the shipment of fresh chilled semen and the freezing of semen, require a good semen quality and quantity from the stallion.

Foaling data are the ultimate proof of the fertility of a stallion (McDowell et al., 1992). Other ways of expressing fertility include non-return rate, per cycle pregnancy rate and per season pregnancy rate (Jasko et al., 1990; McDowell et al., 1992). Fertility results of a stallion may be markedly influenced by the number of mares a stallion covers and the different ways fertility is expressed. Fertility results calculated by using non-return rate tend to overestimate the fertility of a stallion. The best method to predict the fertilizing capability of maiden stallions is the clinical examination of the reproductive organs and laboratory assessment of semen quality (Amann, 1981; Colenbrander et al., 1992).

A positive correlation between daily sperm output and testicular volume has been demonstrated (Pickett et al., 1987; Love et al., 1991). Evaluation of stallion semen is routinely

Received 13 September 1993 done by visual or computerized estimation of the percentage of (progressive) motile spermatozoa and by the assessment of the percentage of cells with normal or abnormal morphology by light microscopy. Visual estimation of the percentage of motile spermatozoa of an ejaculate in comparison with the 'pregnancy' rate obtained from that ejaculate has been used to evaluate stallion semen (Jasko et al., 1990). The motility of fresh or frozen-thawed spermatozoa (assessed by a computerized system for motility evaluation) of 'good' and 'poor' fertilizing stallions has been evaluated, and motility and fertility are positively correlated (Jasko et al., 1988; Blach et al., 1989; Andersson and Katila, 1992). Assessment of morphology by either light or electron microscopy has been performed and evaluation of dye exclusion has been studied (Pickett and Back, 1973; Bielanski and Kaczmarski, 1979). Little is known about the morphology of live spermatozoa of stallions and the variation in the population that occurs. An inverse relationship between the percentage of spermatozoa with primary abnormalities and fertility was reported by Bielanski (1975).

The possible sources of variation in fertility and semen quality of stallions of different breeds or of special populations are not well known. In bulls hereditary effects are found on semen quality and libido (Udala, 1988). Sperm concentration in an ejaculate seems to be heritable, according to experiments with bull twins (Bane, 1954). There is a hereditary positive Downloaded from Bioscientifica.com at 04/26/2023 08:08:20AM 
correlation on male and female reproductive characteristics in cattle (Hansen, 1979; Kieniger, 1983).

Studies involving the reproductive characteristics of horses suggest that the influence of breed is significant (Hendrikse, 1966; Dowsett and Pattie, 1982; Voss et al., 1982; Dowsett and Pattie 1987). Inbreeding negatively affects fertility in horses (Mahon and Cunningham, 1982; Cochran et al., 1984; Klemetsdal and Johnson, 1989). Hereditary aspects may play a role in the quality of stallion semen. Hence, selection can be important. Criteria for selection of a stallion on his reproductive characteristics have to be defined and the variation in sperm quality of the population has to be assessed to select for semen quality. It is then possible to improve semen quality by selective breeding. In the Netherlands young Warmblood stallions are selected on pedigree and conformation. Before they are allowed to breed, they have to pass several tests, including a semen evaluation. The Warmblood population consists of two main types (riding horses and carriage horses), which were one type originally. We investigated whether the two types have an equal semen quality and quantity.

In addition, where some stallions show a relatively poor semen quality and quantity, we investigated whether their offspring inherit this characteristic. We present a statistical distribution of some of the reproductive characteristics of the Dutch Warmblood horse population and the hereditary component in the male reproductive characteristics.

\section{Materials and Methods}

\section{Animals}

The reproductive characteristics of Dutch Warmblood stallions ( $n=398$ ) were assessed from 1987 to 1992 during February and March. The age of the stallions varied between 31 and 37 months. Each animal was assigned to one of the types within the breed: (1) riding $(n=318)$ or (2) carriage $(n=80)$. The stallions were the 100 best each year of a population of about 850 Dutch Warmblood stallions as judged by conformation and pedigree. Semen quality of type 1 and type 2 stallions was compared. The pedigree of the stallion was taken into account when comparing semen quality of semi-siblings $(\geq 3)$ of some stallions (66).

\section{Reproductive characteristics}

Testicles. The scrotum was inspected and palpated and the length and width of the testicles were measured. The testicles were examined for symmetry, conformation, consistency and location. The epididymides were palpated to assess size, symmetry, consistency and location.

Semen quality. Two consecutive ejaculates of each stallion were collected, at $1 \mathrm{~h}$ intervals using a teaser mare as a dummy and collecting the semen with an artificial vagina (Hauptner or Colorado State University model). The ejaculates were filtered through a gauze.

The volume of the ejaculate was measured after filtration of the raw semen through a gauze in a graduated cylinder.
Characteristics of spermatozoa. Progressive motility (\%) of a coded semen sample diluted with an egg-yolk-extender (Rasbech, 1984) (dilution 1:3-1:6, depending on the concentration) was estimated by two experienced technicians: this was done using a prewarmed $\left(37^{\circ} \mathrm{C}\right)$ phase contrast microscope (Olympus model BH2) at $\times 150$.

The sperm concentration was measured with a Bürker Türk counting chamber (haemocytometer) (NIFA, Leeuwarden), correcting for dilution by calculation.

Immediately after semen collection and filtration, a smear of the native semen with anilin blue eosin staining (van de Schaaf, 1952) was prepared and then dried. With this stain the viable spermatozoa were unstained (intact plasma membrane) and the 'dead' spermatozoa were stained red. The morphology and viability of 200 spermatozoa were assessed under bright-field illumination $(\times 1000)$. If the first 200 spermatozoa did not include 100 unstained cells, an additional number of cells were included in the assessment to reach a minimum of 100 unstained cells. Assessment of morphology of spermatozoa was based on the criteria of Bretschneider (1948), which categorize the following characteristics: abnormal acrosome, abnormal head-shape, abnormal neck, abnormal midpiece, curved tail, eccentric tail implant, cytoplasmic droplet neck, cytoplasmic droplet midpiece and normal cells. A sperm cell was placed in one class of abnormality only (the most proximal one). The percentage of morphologically normal live spermatozoa (normal + cytoplasmic droplets + eccentric tail implant) was calculated. The morphology of stained (dead) spermatozoa was not included in this calculation of morphologically normal spermatozoa as this category of cells is non-motile.

The volume $(\mathrm{ml})$ was multiplied by the concentration $\left(10^{6} \mathrm{ml}^{-1}\right)$, the percentage of progressive motile sperms and the percentage of morphologically normal live spermatozoa to obtain the total number of motile morphologically normal spermatozoa.

The average motility, and total number of morphologically normal live spermatozoa and the total number of motile morphologically normal spermatozoa from two ejaculates were also calculated.

\section{Statistical analyses}

The effects of type of stallion (riding or carriage type) and ejaculate number (first or second ejaculate) on semen and testicle characteristics were estimated using the following model (with GLM-SAS; SAS, 1985):

$$
Y_{\mathrm{ijk}}=u+T_{\mathrm{i}}+S\left(T_{\mathrm{j}(\mathrm{i})}+E_{\mathrm{k}}+e_{\mathrm{ijk}}\right.
$$

where $Y=$ dependent variable; $u=$ overall mean; $T=$ type of stallion effect $(\mathrm{i}=1-2) ; S(T)=$ stallion effect nested within the type effect (type $1 \mathrm{j}=1-318$; type $2 \mathrm{j}=1-80$ ); $E$ ejaculate effect $(\mathrm{k}=1-2)$; and $e=$ error.

The semen characteristics of volume and concentration were $\log$ transformed to give a normal distribution in error terms. All mean squares for variables, except those for type of stallion, were tested against the error mean square. The type of stallion effect was tested against the stallion mean square error.

A sire effect on semen and testes characteristics was estimated by using a similar model except that the type of stallion effect was replaced by sire.

Downloaded from Bioscientifica.com at 04/26/2023 08:08:20AM 
Table 1. Reproductive characteristics of the riding type and carriage type Dutch Warmblood stallions

\begin{tabular}{|c|c|c|}
\hline Reproductive characteristic & Riding type & Carriage type \\
\hline Gel-free volume $(\mathrm{ml})$ & $64.3 \pm \quad 0.7^{*}$ & $67.4 \pm 1.5^{*}$ \\
\hline Progressive motility (\%) & $70.0 \pm \quad 0.2^{*}$ & $66.4 \pm \quad 0.3^{*}$ \\
\hline Sperm concentration $\left(10^{6} \mathrm{ml}^{-1}\right)$ & $214.3 \pm 4.9^{*}$ & $174.2 \pm 9.8^{*}$ \\
\hline Total sperm concentration $\left(10^{6}\right)$ & $11652.6 \pm 201.3^{*}$ & $9896.5 \pm 399.4^{*}$ \\
\hline Morphologically normal unstained (\%) & $66.5 \pm \quad 0.2$ & $65.1 \pm \quad 0.5$ \\
\hline $\begin{array}{l}\text { Total number of motile morphologically } \\
\text { normal spermatozoa }\left(10^{\circ}\right)\end{array}$ & $5556.2 \pm 105.3^{*}$ & $4375.1 \pm 209.5^{*}$ \\
\hline $\mathrm{pH}$ & $7.5 \pm \quad 0.0$ & $7.5 \pm \quad 0.0$ \\
\hline
\end{tabular}

Values are LS means \pm SEM. $n=318$ (riding type) and $n=80$ (carriage type).

*Significant difference between types $(P<0.05)$.

The paternal effect of different semen and testicular characteristics was estimated by subjecting the data to analyses using PROC VARCOMP (SAS, 1985). The paternal effect was calculated as four times the variance component of the sire divided by the sum of the sire variance component and the error component (half-sib analyses). The standard deviation of the heritability was estimated according to Falconer (1989). The estimations were made for the two types of stallion and the mean of the two ejaculates.

\section{Results}

The average age of the stallions was approximately 34 months with a range of $31-37$ months. The testicular size (cm) (mean $\pm \mathrm{SD}$ ) of the stallions (type 1 and 2) was left testicle: $9.8 \pm 0.9$ (length) and $5.6 \pm 0.8$ (width), and right testicle: $9.8 \pm 0.9$ (length) and $5.7 \pm 0.7$ (width). No significant difference was seen between the left and right testicle. The percentage of testicular torsions $\left(\geq 180^{\circ}\right)$ was rather low $(<2 \%)$. No abnormalities of size or conformation were observed when palpating the epididymis. The mean values and standard deviations of some semen characteristics were: gel-free volume $(65 \pm 26 \mathrm{ml})$, sperm concentration $(2.061 \pm$ $1.69 \times 10^{6} \mathrm{ml}^{-1}$ ), total number of spermatozoa (1.129 \pm $\left.0.7133 \times 10^{10}\right)$, percentage of progressively motile spermatozoa $(68 \pm 9)$, percentage of morphologically normal live spermatozoa ( $66 \pm 15$ ), total number of morphologically nor$\mathrm{mal}$ unstained spermatozoa $\left(5.307 \pm 3.833 \times 10^{9}\right)$ and $\mathrm{pH}$ $(7.5 \pm 0.2)$. These parameters were calculated over the first and second ejaculate of the two types of the 3-year-old maiden Warmblood stallions. The highest percentage of abnormalities were in the acrosome morphology of the unstained spermatozoa $(6.4 \pm 6.4)$. Other abnormalities frequently observed in the unstained cells were abnormal headshape $(2.8 \pm 2.4 \%)$, abnormal neck $(3.5 \pm 2.9 \%)$, abnormal midpiece $(5.1 \pm 4.1 \%)$ and curved tail $(2.1 \pm 2.1 \%)$. The total percentage of abnormal cells was $22.2 \pm 9.5$ for unstained and $12.9 \pm 7.7$ for stained cells, respectively. The percentage of normal spermatozoa was $32.8 \pm 15.7$ unstained and $16.2 \pm 10.5$ stained. Unstained cells with eccentric tail implant $(2.9 \pm 5.4 \%)$, cytoplasmic droplet at the neck $(5.8 \pm 4.6 \%)$ and midpiece $(4.3 \pm 4.3 \%)$ were added to the normal cells for calculation of the total number of motile morphologically normal spermatozoa. The total number of normal unstained cells (including droplets and eccentric tail implant) was $45.91 \pm 15.41$. The percentage of unstained spermatozoa was $65 \pm 16$. The percentage of normal spermatozoa of the morphologically normal live spermatozoa (including cytoplasmic droplets (neck and midpiece) and eccentric tail implant) was $66 \pm 15$.

The main semen characteristics of the first and second ejaculate (mean $\pm \mathrm{SD}$ ) from the two types of 3-year-old Dutch Warmblood stallions are gel-free volume $(\mathrm{ml}) 61.9 \pm 28.4$ and $67.8 \pm 21.9$, sperm concentration $\left(\times 10^{8} \mathrm{ml}^{-1}\right) 2.855 \pm 1.916$ and $1.267 \pm 0.868$, total number of spermatozoa $\left(\times 10^{10}\right)$ $1.494 \pm 0.7645$ and $0.76408 \pm 0.0264$, percentage progressive motile $67.8 \pm 9.0$ and $70.6 \pm 8.3$, percentage morphologically normal unstained $65.2 \pm 14.6$ and $67.5 \pm 14.4$, total number of motile, morphologically normal spermatozoa $\left(\times 10^{9}\right)$ $6.8806 \pm 4.3984$ and $3.7445 \pm 2.2815$ and $\mathrm{pH} 7.5 \pm 0.1$ and $7.6 \pm 0.1$, respectively. A significant difference $(P<0.05)$ in all the given semen parameters was present between the first and second ejaculate. The sperm concentration in the second ejaculate was almost half of the concentration in the first ejaculate which was also expressed in the total number of spermatozoa and the total number of motile morphologically normal spermatozoa.

The percentage of progressively motile spermatozoa and the percentage of morphologically normal unstained spermatozoa significantly increased in the second ejaculate.

The reproductive characteristics of the riding and the carriage type across two ejaculates are shown (Table 1).

No significant difference was seen in testicular size, gel-free volume, $\mathrm{pH}$ and the percentage of morphologically normal live spermatozoa of the different types. A significant difference $(P<0.05)$ was obtained for progressive motility, sperm concentration, total number of spermatozoa and total number of morphologically normal live spermatozoa of the two types for the two ejaculates.

The semen quality of semi-siblings (more than three per stallion) over two ejaculates regarding percentage morphologically normal live spermatozoa $(P<0.07)$ and total number of motile morphologically normal spermatozoa $(P<0.07)$ was correlated (Table 2). Sperm concentration $\left(10^{6} \mathrm{ml}^{-1}\right)$ Downloaded from Bioscientifica.com at 04/26/2023 08:08:20AM 
Table 2. Paternal effects in semen quality

\begin{tabular}{ll}
\hline Reproductive characteristic & $P$ value* \\
\hline Gel-free volume $(\mathrm{cm})$ & $<0.03$ \\
Progressively motile $(\%)$ & $<0.03$ \\
Sperm concentration $\left(10^{6} \mathrm{ml}^{-1}\right)$ & $<0.0005$ \\
Total number of spermatozoa $\left(10^{6}\right)$ & $<0.11$ \\
Morphologically normal unstained $(\%)$ & $<0.07$ \\
Total number of motile morphologically & \\
normal spermatozoa $\left(10^{6}\right)$ & $<0.07$ \\
pH & $<0.63$ \\
\hline
\end{tabular}

${ }^{*} P$ value of reproductive characteristics of semi-siblings $(>3)$ of 66 stallions.

$(P<0.0005)$, gel-free volume $(P<0.03)$ and percentage of progressively motile spermatozoa $(P<0.03)$ were significantly different. No significant correlation was seen in testicular size, total number of spermatozoa and $\mathrm{pH}$.

\section{Discussion}

Reproductive characteristics of stallions as of other species are influenced by several factors. Season and age affect testes size (Pickett et al., 1989). The stallions in this study were of the same age and examined in February and March, which makes a statistical evaluation of reproductive characteristics more reliable. The size of the testicles of the Warmblood stallion was similar to that of other stallions (Pickett et al., 1987; Love et al., 1991). The size of the testes, which is highly heritable in bulls (Coulter et al., 1976), did not show a heritable effect in this stallion population. This is probably due to the pre-selections on equality and size of the testicles at the conformation test. Stallions with testicles that were too small (two standard deviations less than the mean value) or unequal (one smaller by $2 \mathrm{SD}$ ) were not accepted by the studbook, because a lower sperm production can be expected (McKinnon and Voss, 1993). Sperm production is influenced by age and season (Pickett et al., 1989); the method of collection also influences the ejaculate obtained, but all the semen samples were collected under the same conditions in this study. The semen characteristics of the total population were similar to those found in stallions by other workers (Dowsett and Pattie, 1987; Pickett et al., 1987). Only the volume of the ejaculate of the Warmblood stallions seems to be larger than that of other breeds. Progressive motility of spermatozoa is essential for fertility and abnormally motile spermatozoa may cause abnormal development of the zygote after fertilization of the oocyte (McKinnon and Voss, 1993).

The morphology of spermatozoa plays an important role in fertility in stallions (Dowsett and Pattie, 1982; Jasko et al., 1990). The acrosome is particularly important in the fertilizing process, which means that a stallion with a high percentage of acrosomal abnormalities might be considered subfertile. The cytoplasmic droplets are counted as normal (Dowsett and Pattie, 1982). However, Jasko et al. (1990) considered that spermatozoa with proximal cytoplasmic droplets were abnormal and less fertile. The results obtained for these morphology parameters are highly reproducible for each stallion (Jasko et al., 1990), which means that it is possible to select for stallions with spermatozoa of good morphology.

There was a large variation in the reproductive characteristics of the Warmblood stallions within the population, which makes it of interest to determine whether part of this variation can be explained by heritable effects.

The semen characteristics of the first and second ejaculate differed significantly. For most of the stallions the first ejaculate was the actual first ejaculate and some of the young stallions have difficulties with the first ejaculation. These stallions often have a better second ejaculate with a higher total number of spermatozoa. The majority of the stallions have a higher percentage of progressive motile spermatozoa and a higher percentage of morphologically normal live spermatozoa in the second ejaculate, which might be because the first ejaculate was the first ejaculate the stallion ever produced. This first ejaculate might contain a relatively high number of aged spermatozoa. The total number of spermatozoa in the second ejaculate was $55 \%$ of the first ejaculate, which is in agreement with Bielanski (1964).

The minimal values of parameters of semen quality of the young stallions for registration in the studbook is a mean total number of progressive motile morphologically normal spermatozoa of $2000 \times 10^{6}$ and a mean of $50 \%$ for motility and morphology over the two ejaculates. Every year approximately $8 \%$ of the stallions do not pass this semen test. Young stallions that acquire the minimal values of parameters of the semen cause problems during the breeding season when they have to serve more than 50 mares or when semen has to be stored and transported. Prediction of the breeding potency of stallions can therefore be of great benefit for the studfarm owner and for the mare owner.

The Dutch Warmblood breed was originally one population, whereas the present breed has been divided into different types based on conformation and gaits. There is a significant difference in the semen quality of the two types of stallions, which means that they can be considered as two different populations. After selection into riding and carriage type took place, a difference in semen quality arose between the two types, indicating that there is a genetic effect on semen characteristics. In general the carriage type shows a poorer semen quality and quantity than does the riding type. A breed difference in semen quality was also shown by Dowsett and Pattie (1987) and Colenbrander et al. (1992).

There is correlation of semen quality and quantity in semi-siblings and different stallion lines show a significant difference in sperm quality and quantity. For calculating heritability, the group size of semi-siblings should be between 20 and 30 (Falconer, 1989), but this is difficult to achieve in horses. These data showed that there was a tendency to heritability, but the variation was quite high, because the family size varied from three to eight male offspring per stallion. It would be useful to exclude from breeding stallions that pass poor semen quality on to their offspring. The important conclusion of this study is that it is beneficial to select for reproductive characteristics and for breeding and to give preference to stallion lines with a good semen quality. The next step will be to compare fertility data of fresh and frozen semen with sperm quality for a number of these stallions. In addition other laboratory tests, Downloaded from Bioscientifica.com at 04/26/2023 08:08:20AM 
for example the hemizona assay, might give additional information for prediction of the fertilizing capacity of stallions (Fazeli et al., 1993).

The authors would like to thank H. Puyk, P. Ursem and A. R. Zandee for their technical assistance.

\section{References}

Amann RP (1981) A critical review of methods for evaluation of spermatogenesis from seminal characteristics Journal of Andrology 2 37-58

Andersson M and Katila T (1992) Evaluation of frozen-thawed stallion semen with a motility analyser 12 th International Congress of Animal Reproduction 1837-1839

Bane A (1954) Studies on monozygous cattle twins. IV. Sexual functions of buils in relation to heredity, rearing intensity and somatic conditions Acta Agriculturae Scandinavica 4 95-208

Bielanski W (1964) Comparison of the number of spermatozoa in the successive ejaculates during depletion tests in stallions, rams and bulls Proceedings of the Fifth International Congress of Animal Reproduction and AI 4 645-650

Bielanski W (1975) The evaluation of stallion semen in aspects of fertility control and its use for artificial insemination Joumal of Reproduction and Fertility Supplement 23 19-24

Bielanski W and Kaczmarski F (1979) Morphology of spermatozoa in semen from stallions of normal fertility Journal of Reproduction and Fertility Supplement 27 39-45

Blach EL, Amann RP, Bowen RA and Frantz D (1989) Changes in quality of stallion spermatozoa during cryopreservation: plasma membrane integrity and motion characteristics Theriogenology 2 283-298

Bretschneider LH (1948) Een normentafel ten gebruike bij de morphologische beoordeling van stierensperma Tijdschrift voor Diergeneeskunde 73 421-433

Cochran ED, MacCluer JW, Weitkamp LR, Pfennig DW and Boyce AJ (1984) Inbreeding and reproductive performance in Standardbred horses Joumal of Heredity 75 220-224

Colenbrander B, Puyk H, Zandee AR and Parlevliet JM (1992) Evaluation of the stallion for breeding Acta Veterinaria Scandinavica Supplementa 88 29-38

Coulter GH, Rounsaville RH and Foote RH (1976) Heritability of testicular size and consistency in Holstein bulls Joumal of Animal Science 43 9-12

Dowsett KF and Pattie WA (1982) Characteristics and fertility of stallion semen Joumal of Reproduction and Fertility Supplement 32 1-8

Dowsett KF and Pattie WA (1987) Variation in characteristics of stallion semen caused by breed, age, season of year and service frequency Journal of Reproduction and Fertility Supplement 35 645-647

Falconer DS (1989) Introduction to Quantitative Genetics (3rd Edn) Longman Scientific and Technical, Essex

Fazeli AR, Steenweg W, Bevers MM, Bracher V, Parlevliet J and Colenbrander B (1993) Use of sperm binding to homologous hemizona pellucida to predict stallion fertility Equine Veterinary Journal Supplement 15
Hansen H (1979) Genetic investigations on male and female fertility Livestock Production Science 6 325-334

Hendrikse J (1966) Het sperma van normaal bevruchtende dekhengsten Tijdschrift voor Diergeneeskunde 91 300-311

Jasko DJ, Little TV, Smith K, Lein DH and Foote RH (1988) Objective analysis of stallion sperm motility Theriogenology 6 1159-1167

Jasko DJ, Lein DH and Foote RH (1990) Determination of the relationship between sperm morphologic classifications and fertility in stallions: 66 cases (1987-1988) Journal of the American Veterinary Medicine Association 197 389-393

Kieniger J (1983) Populationsgenetische analysen für fruchtbarkeitsmerkmale beim Rind Dissertation Hohenheim

Klemetsdal G and Johnson M (1989) Effect of inbreeding on fertility in Norwegian Trotter Livestock Production Science 21 263-272

Love CC, Garcia MC, Riera FR and Kenney RM (1991) Evaluation of measures taken by ultrasonography and caliper to estimate testicular volume and predict daily sperm output in the stallion Journal of Reproduction and Fertility Supplement 44 99-105

McDowell KJ, Powell DG and Baker CB (1992) Effect of booksize and age of mare and stallion on foaling rates in thoroughbred horses Journal of Equine Veterinary Science 6 364-367

McKinnon AO and Voss JL (1993) Equine Reproduction. Lea and Febiger Philadelphia

Mahon GAT and Cunningham EP (1982) Inbreeding and the inheritance of fertility in the Thoroughbred mare Livestock Production Science 9 949-953

Pickett BW and Back DG (1973) Procedures for preparation, collection, evaluation and insemination of stallion semen Colorado State University Experimental Station General Series 935

Pickett BW, Voss JL, Bowen RA, Squires EL and McKinnon AO (1987) Seminal characteristics and total scrotal width (T.S.W.) of normal and abnormal stallions Proceedings of the 33rd Annual American Association of Equine Practitioners Convention 487-518

Pickett BW, Amann RP, McKinnon AO, Squires EL and Voss JL (1989) Management of the Stallion for Maximum Reproductive Efficiency, II. Bulletin 5 Colorado State University. Collins, Colorado

Rasbech NO (1984) Instrumentalinseminering i hesteavlen Dansk Veterinaer Tidsskrift $67111 / 6$

SAS (1985) SAS User's Guide Statistical Analyses System Institute Inc., Cary, NC

Schaaf A van de (1952) Vitaalkleuring van stierensperma met een oplossing van anilineblauw en eosine Tijdschrift voor Diergeneeskunde 77 815-818

Udala U (1988) Dere genetishce Einflus auf die Spermaqualität von Bullen in Abhangigkeit von ihrer Abstammung Tierzucht 42 (5) 234-235

Voss JL, Pickett BW and Loomis PR (1982) The relationship between semen characteristics and fertility in Thoroughbred stallions Journal of Reproduction and Fertility Supplement 32 635-636 